\title{
Leadership and Management Competencies for Hospital Managers: A Systematic Review and Best-Fit Framework Synthesis
}

This article was published in the following Dove Press journal:

Journal of Healthcare Leadership

\author{
Edris Kakemam (D) \\ Zhanming Liang ${ }^{2}$ \\ Ali Janati (D) \\ Morteza Arab-Zozani $\mathbb{( D D}^{3}$ \\ Bahram Mohaghegh ${ }^{4}$ \\ Masoumeh Gholizadeh' \\ 'Iranian Center of Excellence in Health \\ Management (IceHM), Department of \\ Health Services Management, School of \\ Management and Medical Informatics, \\ Tabriz University of Medical Sciences, \\ Tabriz, Iran; ${ }^{2}$ School of Psychology and \\ Public Health, La Trobe University, \\ Melbourne, Australia; ${ }^{3}$ Social \\ Determinants of Health Research Center, \\ Department of Public Health, School of \\ Health, Birjand University of Medical \\ Sciences, Birjand, Iran; ${ }^{4}$ Department of \\ Public Health, School of Health, Qom \\ University of Medical Sciences, Qom, Iran
}

Correspondence: Masoumeh Gholizadeh Department of Health Services Management, School of Management and Medical Informatics, Tabriz University of Medical Sciences, Tabriz, Iran

Email mgholizadehm@gmail.com
Objective: Competent managers are vital to the productivity and service quality of healthcare organizations and the sustainability of the healthcare system. To improve their management competence, understanding of management competency requirements is important. The purpose of this study was to synthesize the evidence related to the leadership and management competencies in healthcare organizations through the best-fit method.

Methods: A systematic review of literature published between 2000 and 2020 was performed to identify studies focusing on confirming and/or identifying the competency requirements of hospital managers. The best-fit framework synthesis method was used to map the identified competencies and associated behavioral items against the validated management competency assessment program (MCAP) management competency framework.

Results: Twelve studies were identified for inclusion in the review. The mapping of the identified competencies and behavioral items generated a competency model for hospital managers that can apply for different healthcare context. The new competency model includes the following seven core leadership and management competencies: evidence-informed decision-making, operations, administration and resource management, knowledge of healthcare environment and the organization, interpersonal, communication qualities and relationship management, leading people and organisation, enabling and managing change, and professionalism.

Conclusion: This review and the mapping of the competencies identified in previous studies against the validated MCAP framework has resulted in the recommendation for an extended leadership and management competency framework for health service managers. It provides guidance for the formulation of training and development directions for the health service management workforce in a different healthcare context.

Keywords: competencies, competency development, management, leadership, hospital managers, best-fit framework, systematic review

\section{Introduction}

Today's healthcare systems face multiple challenges. These include rising healthcare needs and costs as a result of a growing ageing population with noncommunicable diseases and multiple pathologies, exacerbated by a surge of new medical technologies. These problems are further compounded by workforce maldistribution and shortages, and poor quality and safety of service provision. ${ }^{1-3}$ In addition, inequities in health, lack of access to quality health care and a poorly skilled health workforce represent some of the major challenges facing many countries in the Eastern Mediterranean Region., 
As a result, reforms have been implemented to improve the effectiveness and efficiency of service delivery at the organizational level including streamlining the management structure, focusing more on performance improvement and benchmarking service outcomes. ${ }^{6,7}$ The changing healthcare landscape and requirements of service delivery require a new skillset for health professionals; therefore, a novel managerial approach is needed to lead and manage such transition and consolidation. ${ }^{8,9}$ Such changes inevitably impact on how healthcare managers work and the competencies required to make their work effective. ${ }^{7,10,11}$

Since the late1980s, there have been profound changes in the health system in Iran. More significant transformation has been expected after the launch of the Health Sector Evolution Plan in 2014 setting the reform direction for the Iranian health system which included a hospitaloriented transformation of the health service in order to address the substantial increase in healthcare costs over the past decades and improve the accessibility, efficiency and quality of hospital services. ${ }^{12}$ The Iranian healthcare system spends between $55 \%$ and $80 \%$ of its healthcare budget on hospitals. ${ }^{13-15}$

Iranian hospital management positions are unregulated with no specific registration or credentialing requirements. Competency requirements for health managers have not been clearly established providing limited guidance to the design of formal and informal training and development programs. Although Bachelor, Master, and Doctorate level degrees with a specialization in healthcare management/ health administration are on offer together with two informal training programs offered by the MOHME and a private institution around the country, there is no evidence that graduates or participants have acquired the necessary skills and competences for management. This is largely a result of the unclear focus on management competency development by informal and formal training. Managers are not often selected on the basis of their capacity and competency, predominantly in the public sector. $^{5,16,17}$

The review of the Bachelor and Master programs in healthcare management/health administration confirms the ad hoc design adopted for developing the teaching and training curriculum without a universal guiding competency framework. ${ }^{5,17}$ Recent studies indicate a huge diversity in terms of overall focus and content requirements amongst the Iranian formal and informal educational programs in health service management and a lack of agreement on the approach taken to management development. ${ }^{16,18}$

Managers are required to demonstrate core competencies consisting of knowledge, skills and attitudes to perform the managerial tasks and fulfil their managerial responsibilities. ${ }^{19}$ The need for developing leadership and management competencies in hospitals and accepting management as a recognized profession are constantly reinforced. $^{20,21}$ However, efforts to develop competent health-care managers and leaders have proven insufficient without a clear focus and direction. ${ }^{20,22,23}$ Such deficiency is more prominent in the under-resourced and less developed countries such as Iran.

International literature has confirmed the existence of core leadership and management competencies for health service managers ${ }^{24,25}$ with a number of proposed management competency frameworks. Such efforts can be used to benefits healthcare systems in different countries and context as a general guide to setting the training and development direction for healthcare managers.

The aim of the paper is to present and discuss the findings of a systematic literature review aimed at answering the following questions:

1. What are the core leadership and management competencies, which have been consistently recognised as required by health service managers?

2. What are the behavioral items that can be used to demonstrate/measure each of the core competencies?

It is expected that the findings of the study can be used to guide the improvement of current health administration training curriculum in Iranian Universities and guide the recruitment and provision of professional development for existing Iranian hospital managers.

\section{Methods}

\section{Study Method}

We conducted a systematic review of literature published between year 2000 and 2020 focused on leadership and management competencies for hospital managers in the second half of 2019. This publication period was chosen because it signalled the significant development in the understanding of leadership and management competency in the health sectors. ${ }^{11}$ Papers were selected and included according to the Preferred Reporting Items for Systematic Reviews and Meta-analysis (PRISMA). ${ }^{26}$ 


\section{Study Inclusion and Exclusion Criteria Inclusion Criteria}

The following inclusion criteria were used as a guide for searching and screening the articles: 1) papers were published between 2000 and 2020;2) articles were published in the English language; 3) empirical/original studies focusing on the identification and development of leadership or management competencies in hospitals.

\section{Exclusion Criteria}

Publications that did not go through a peer-review process and articles that did not present results of empirical studies such as book reviews, commentaries and opinion articles were excluded from the analysis.

\section{Search Strategy and Data Sources}

Four databases were searched, including PubMed, Web of Science (ISI), Emerald, and Scopus. These databases were chosen because the majority of the studies focusing on health services and health service management research are indexed in these databases. The references used in the journal articles included in the final analysis were also screened to identify relevant studies. But the screening of the references did not result in new articles to be included. Keywords were searched in title and abstract of papers via an advanced search in databases. The following keywords/ combination of keywords was used to guide the search: hospital manager* OR hospital management OR hospital leadership OR healthcare leadership OR health service manager* OR health manager* OR healthcare manager*in Title and Abstract AND (skill* OR competenc* in Title and Abstract (see Appendix 1)).

\section{Study Quality Assessment}

The quality of selected papers was assessed using the mixed methods appraisal tool (MMAT) ${ }^{27}$ The MMAT is effective as it is designed to appraise the most common types of empirical studies including qualitative, quantitative and mixed-methods studies. ${ }^{28}$ The MMAT is based on constructionist theory and has already been used by more than 100 systematic mixed study reviews (http://mixed methodsappraisaltoolpublic.pbworks.com/). Two of the review authors (EK, MAZ) independently appraised the included studies based on MMAT. When there were disagreements between reviewers in the study quality assessments, this was resolved by a third reviewer (MGH).

The assessment process started by responding to the following two screening questions.
1. Are there clear research questions?

2. Do the collected data allow addressing the research questions?

Each included study was then rated in the appropriate category of criteria as either "yes", "no" or "can't tell". While calculation of an overall score is discouraged, the MMAT provides a more detailed presentation of the ratings of each criterion to better inform the quality of included studies (Appendix 2).

\section{Study Selection Process and Data Extraction}

After conducting the search, the retrieved papers were imported into the EndNote software (V.X8), and duplicate papers deleted. Two authors (EK, MAZ) performed the initial screening of article titles and abstracts for their relevance to determine articles that warranted full-text reading. After screening the studies, the data were extracted in order to meet the research objectives and questions. To this end, a data extraction form was initially designed and tested on five randomly selected papers. The form was designed and completed for each article in MS Excel software. Two reviewers (EK, MAZ) independently extracted the following information: the surname of the first author, year, country of origin, type of study, types of participant, settings, data collection methods and main findings. At this stage, one of the authors extracted the data from the selected articles, and the second author examined the data. When there were disagreements between reviewers in the paper review and selection process, a third reviewer (AJ) was involved to make a final decision.

\section{Data Synthesis}

Three review authors (ZL, EK and MAZ) independently synthesized the data which was analyzed using the best-fit framework synthesis method to identify similarities and differences between the literature and the selected model that details of the studies would map against. ${ }^{29,30}$ Based on the best-fit method, the selected framework might change during the research and data collection, whereby a new conceptual framework could be generated. Under this method, both deductive and inductive approaches were therefore used for data analysis. ${ }^{31}$

During this process, the papers that best met the topic requirements were selected. Competencies/skills identified in 
the studies were mapped against the themes and sub-themes of the selected management competency model (MCAP).

The specific study process was guided by the understanding of the relationship between tasks and competencies (Figure 1), as detailed in Liang's study on the impact of health reform on the competency requirements of NSW senior health executives conducted in $2004 .{ }^{19}$ In practice, the confirmation of major tasks of managers (the top of the pyramid) can guide the identification of core competencies required in order to perform these tasks effectively. Each competency consists of a set of knowledge, skills, attitudes and behaviors that were essential for the demonstration of the competency.

Following the study conducted in NSW, Liang and colleagues completed another study between 2011 and 2015 to identify the core competencies required for health services managers in Australia together with detailed behavioral items that could measure each of the competencies. As a result, a management competency framework - the MCAP framework - was developed and validated. ${ }^{32-34}$ In the present study, the MCAP framework was selected as the primary framework for grouping, comparing and contrasting competencies of health services managers. All competencies extracted from selected studies were compared and regrouped into the following six core management competencies as included in the MCAP framework:

1. Evidence - evidence-informed decision-making;

2. Resources - operations, administration and resource management;

3. Knowledge - knowledge of healthcare environment and the organisation

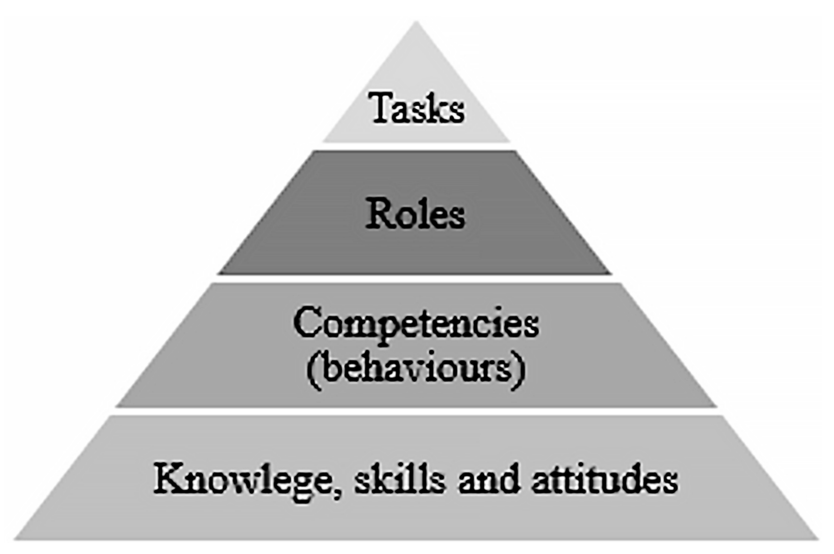

Figure I The pyramidal relationship between tasks, roles and competencies (adapted from Liang et al 2013). ${ }^{32}$
4. Communications - interpersonal, communication qualities and relationship management;

5. Leadership - leading people and organisation, and

6. Change - enabling and managing change.

We used the MCAP Framework because it is the most recent and fully validated framework for health service managers ${ }^{33}$ and the framework includes behavioral items that can measure each of the core leadership and management competencies. Using the best-fit method, it was expected that the mapping of the identified competencies/ skill/behavioral items from the studies against the selected MCAP framework may lead to the identification of competencies/skills/behavioral items that did not fit into the MCAP framework (Table 1). As a result, a revised management competency framework might emerge. Competencies and behavioral items were initially coded as semantic units. In the first stage, competencies and behavioral items related to the dimensions of the initial model were inserted deductively through explicit analysis.

The research team contacted authors of the MCAP framework to obtain details of the behavioral items for each competency and sub-themes in grouping the behavioral items for each of the competencies. Details of the

Table I MCAP Competencies and Sub-Themes ${ }^{34}$

\begin{tabular}{|c|c|}
\hline $\begin{array}{l}\text { MCAP } \\
\text { Competencies }\end{array}$ & Sub-Themes \\
\hline Evidence & $\begin{array}{l}\text { I-Evidence appraisal } \\
\text { 2-Evidence application and decision making } \\
\text { 3-Evaluation of decision }\end{array}$ \\
\hline Resources & $\begin{array}{l}\text { I-Staff management } \\
\text { 2-Financial management } \\
\text { 3-Organisation management }\end{array}$ \\
\hline Knowledge & $\begin{array}{l}\text { I-Knowledge of healthcare environment } \\
\text { 2-Knowledge of organisation } \\
\text { 3-Application of knowledge in legal and quality } \\
\text { practices }\end{array}$ \\
\hline Communications & $\begin{array}{l}\text { I-Relationship management and teamwork } \\
\text { 2-Communication } \\
\text { 3-Personal quality }\end{array}$ \\
\hline Leadership & $\begin{array}{l}\text { I-Leading people and teams } \\
\text { 2-Leading organisation } \\
\text { 3-Leader quality }\end{array}$ \\
\hline Change & $\begin{array}{l}\text { I-Change preparation } \\
\text { 2-Change implementation and evaluation } \\
\text { 3-Leader quality in change }\end{array}$ \\
\hline
\end{tabular}


subthemes for each of the six competencies are listed in Table 1. The sub-themes and relevant grouping of the behavioral items are included in Appendix 3.

Stage one: the purpose of this stage was to confirm whether competencies identified in the selected studies could be included in the existing MCAP framework. At this stage, each competency identified including its description (some cases not called behavioral items) was compared with the relevant competencies in the MCAP framework. The reviewing of the behavioral items simultaneously was an important step as the name of the competencies may have differed, but the behavioral items or descriptions included were compatible with the MCAP competencies. In such cases, they should be included as part of the MCAP framework, rather than being treated as newly identified competencies. In the case that competencies fitted into the MCAP framework, but with additional behavioral items identified from other studies, these items would be included in the existing competencies in the revised framework.

Stage two: In the second stage, any competencies that were not included in the MCAP framework were classified inductively through an open coding method. At this stage, competencies together with their associated behaviors identified in the recent studies that were not been included in the MCAP framework were confirmed and included in the revised framework to reflect the most recent findings of leadership and management competency requirements for health service managers. The above two phases were completed and cross-checked by the first two named authors to ensure accuracy and consistency. Finally, the findings of these two stages were put together and a new framework was created.

\section{Results}

In the initial search, 5261 articles were found in the four selected databases by keyword search as explained earlier. The text of 79 studies was read in full and finally, 12 studies (details included in Table 2) were selected based on the inclusion and exclusion criteria. Figure 2 shows the process of searching and selecting studies and the total number of studies/papers included at each step of the review.

\section{Characteristics of the Selected Studies}

All studies were published between 2003 and 2019. Five studies $^{16,35-38}$ were conducted in Asia (Iran, China, Thailand, Indonesia and Vietnam), six studies were completed in four different countries: two in the USA, ${ }^{39,40}$ two in Australia, ${ }^{32,34}$ two in South Africa, ${ }^{41,42}$ and one study ${ }^{43}$ in Finland.

All of the studies identified included hospital managers as part of their study population such as chief executive officers/heads of the hospital, chief operating officers, nursing managers, finance managers, and human resources managers. From a methodological standpoint, five studies utilised a qualitative method, four studies included mixedmethods and three investigations used quantitative descriptive methods. The characteristics of the studies included are shown in Table 2.

All the selected studies were evaluated for quality to confirm their inclusion for analysis. The qualitative studies met the tool assessment requirements. Among the mixedmethods studies, two of them did not state sufficient logic of utilizing this method. None of the cross-sectional studies mentioned the sampling methods. Using the MMAT tool, the quality of the studies was evaluated (see Appendix 2: Tables A1- 3 ).

The analysis of the 12 studies confirmed that the term competency had not been applied consistently to all studies and not all competencies identified in the studies included detailed descriptions of the behavioral items used to measure them consistently. Instead, knowledge, skills, behaviors and competencies were used interchangeably in some of the studies. Without changing their meaning and what they represented, all these items were carefully considered and entered into the last column of Appendix 3 according to their relevance to the subthemes of the MCAP framework. These items were then compared carefully with the behavioral items from the MCAP framework included in column three. The authors of the MCAP framework were contacted to cross-check the accuracy of the step.

The completion of the above steps confirmed that in addition to the MCAP core competencies and associating behavioral items, the competency of "professionalism" is to be included in the new global competency framework that can be used to guide health service management training and development in different healthcare context.

Appendix 3 provides details of the MCAP competencies and behavioral items (grouped into sub-themes), and all items (including non-behavioral items) identified in other studies. Appendix 3 mentioned above provides a summative view of the MCAP behavioral items that had not been fully covered or partially covered by other studies, the items identified from non-MCAP studies that cannot be found within the MCAP framework, and also 
Table 2 Characteristics of Included Studies (Listed in the Reverse Order of the Year of Publications)

\begin{tabular}{|c|c|c|c|c|c|c|}
\hline $\begin{array}{l}\text { Author, } \\
\text { Year }\end{array}$ & Country & $\begin{array}{l}\text { Type of } \\
\text { Participants }\end{array}$ & $\begin{array}{l}\text { Study } \\
\text { Design }\end{array}$ & Data Collection Method & Setting & $\begin{array}{l}\text { Number of } \\
\text { Competencies }\end{array}$ \\
\hline $\begin{array}{l}\text { Gunawan } \\
\text { et al } 2019^{38}\end{array}$ & Indonesia & $\begin{array}{l}\text { First-line nurse } \\
\text { managers }\end{array}$ & $\begin{array}{l}\text { Mixed } \\
\text { methods }\end{array}$ & $\begin{array}{l}\text { Integrative review, interviews } \\
\text { with experts and survey }\end{array}$ & Public hospitals & $\begin{array}{l}7 \text { Core } \\
\text { competencies and } \\
43 \text { behavioral items }\end{array}$ \\
\hline $\begin{array}{l}\text { Liang et al } \\
2018^{34}\end{array}$ & Australia & $\begin{array}{l}\text { Health service } \\
\text { managers }\end{array}$ & $\begin{array}{l}\text { Mixed } \\
\text { methods }\end{array}$ & $\begin{array}{l}\text { Position description analysis } \\
\text { (PDA), focus group discussions } \\
\text { and online surveys }\end{array}$ & $\begin{array}{l}\text { Hospitals and } \\
\text { Community } \\
\text { health services }\end{array}$ & $\begin{array}{l}6 \text { Core } \\
\text { competencies and } \\
79 \text { behavioral items }\end{array}$ \\
\hline $\begin{array}{l}\text { Van Tuong \& } \\
\text { Thanh, } \\
2017^{36}\end{array}$ & Vietnam & Hospital managers & $\begin{array}{l}\text { Mixed } \\
\text { methods }\end{array}$ & PDA, survey & Public hospitals & $\begin{array}{l}12 \text { Core } \\
\text { competencies and } \\
74 \text { behavioral items }\end{array}$ \\
\hline $\begin{array}{l}\text { Barati et al } \\
2016^{16}\end{array}$ & Iran & Hospital managers & Qualitative & $\begin{array}{l}\text { Interviews and focus group } \\
\text { discussions }\end{array}$ & Public hospitals & 8 Competencies \\
\hline $\begin{array}{l}\text { Luo et al } \\
2016^{35}\end{array}$ & China & Nurse managers & Qualitative & In-depth interviews & Hospitals & 19 Competencies \\
\hline $\begin{array}{l}\text { Kantanen } \\
\text { et al } 2015^{43}\end{array}$ & Finland & Nurse managers & $\begin{array}{l}\text { Quantitative } \\
\text { descriptive }\end{array}$ & $\begin{array}{l}\text { Literature review, expert panel } \\
\text { and survey }\end{array}$ & Hospitals & 12 Competencies \\
\hline $\begin{array}{l}\text { Liang et al } \\
2013^{32}\end{array}$ & Australia & $\begin{array}{l}\text { Hospital managers at } \\
\text { the middle and } \\
\text { senior levels }\end{array}$ & $\begin{array}{l}\text { Mixed } \\
\text { methods }\end{array}$ & $\begin{array}{l}\text { PDA, Focus group discussions and } \\
\text { online survey }\end{array}$ & Hospitals & 6 Competencies \\
\hline $\begin{array}{l}\text { Wongprasit, } \\
2013^{37}\end{array}$ & Thailand & Hospital directors & Qualitative & In-depth interview & Private hospitals & $\begin{array}{l}6 \text { Competencies } \\
\text { and } 26 \text { behavioral } \\
\text { items }\end{array}$ \\
\hline Pillay, $2010^{42}$ & $\begin{array}{l}\text { South } \\
\text { Africa }\end{array}$ & $\begin{array}{l}\text { Senior nursing } \\
\text { managers }\end{array}$ & $\begin{array}{l}\text { Quantitative } \\
\text { descriptive }\end{array}$ & Review and survey & $\begin{array}{l}\text { Public and } \\
\text { private hospitals }\end{array}$ & $\begin{array}{l}7 \text { Competencies } \\
\text { and } 5 \mathrm{I} \text { behavioral } \\
\text { items }\end{array}$ \\
\hline Pillay, $2008^{41}$ & $\begin{array}{l}\text { South } \\
\text { Africa }\end{array}$ & Hospital managers & $\begin{array}{l}\text { Quantitative } \\
\text { descriptive }\end{array}$ & Review and survey & $\begin{array}{l}\text { Public and } \\
\text { private hospitals }\end{array}$ & $\begin{array}{l}5 \text { Competencies } \\
\text { and } 39 \text { behavioral } \\
\text { items }\end{array}$ \\
\hline $\begin{array}{l}\text { Sherman } \\
\text { et al } 2007^{40}\end{array}$ & USA & Nurse managers & Qualitative & Face-to-face interviews & Hospitals & 6 Competencies \\
\hline $\begin{array}{l}\text { Connelly } \\
\text { et al } 2003^{39}\end{array}$ & USA & Charge nurses & Qualitative & Interviews & Hospitals & $\begin{array}{l}4 \text { Competencies } \\
\text { and } 54 \text { behavioral } \\
\text { items }\end{array}$ \\
\hline
\end{tabular}

items that may considered to be added to an additional competency: Professionalism.

\section{Discussion}

In the past 20 years, only a handful of studies have been conducted to understand the competency requirements of health service managers. This may be partially due to the fact that health service management competency is a new and an emerging field of study, ${ }^{32}$ and the concept of competency-based education and training has only been adopted by small number of health service management training programs mainly in the US, UK and few European countries and more recently in Australia. ${ }^{33}$ However, the systematic literature review was able to substantiate the core competencies required by health service managers. These inclusive competencies can be validated and used in countries yet to develop their own management competency framework to guide training and developing their health service management workforce. However, it is worth noting that leadership and 


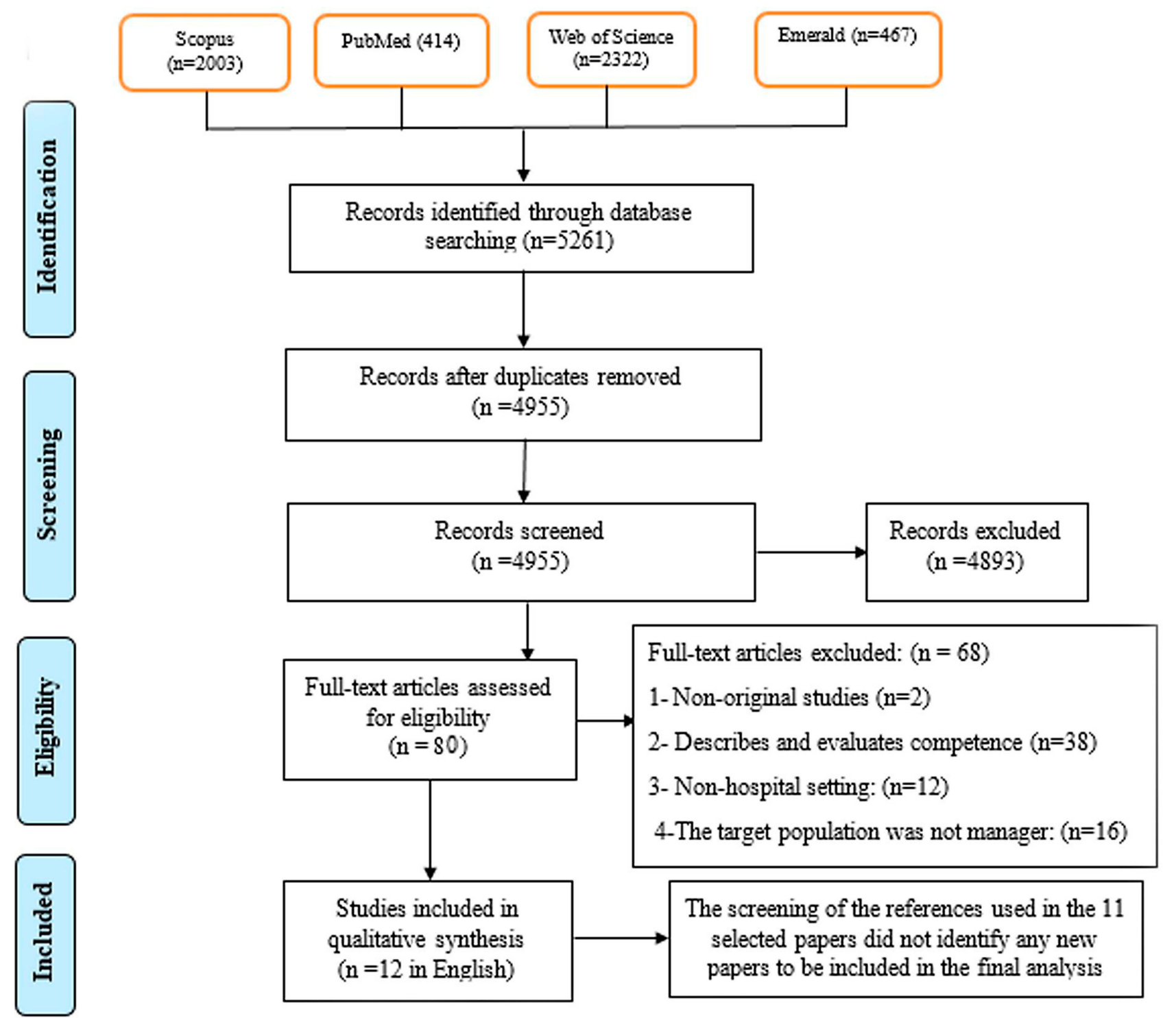

Figure 2 The process of studies selection.

management competencies are context sensitive; competencies and their associated behavioral items identified in the studies conducted in one healthcare context or country may not be entirely applicable to other contexts. ${ }^{33}$ For example, behavioral items in each of the competencies may not be equally important to hospital managers in Australia and Iran. In addition, behavioral items in each of the competencies may not be equally important between different management levels and types of management positions. For example, behavioral items that are important to executive directors of hospitals may not be seen as equally important to directors of nursing if the core tasks they need to perform are different (refer to Figure 1 and explanation earlier).
The mapping of the competencies identified in the studies conducted over the past 20 years using the MCAP framework and associated behavioral items as the guiding framework confirms the following inclusive competency framework (Figure 3) for health service managers which will be validated in the Iranian healthcare context in the next step of the research.

The six core competencies that have been included in the MCAP framework as detailed earlier in the paper have been well discussed in the literature and agreed by recent studies. Hence, there is no doubt of their importance to be included as core competencies for health service managers to acquire in order to perform their managerial responsibilities effectively. ${ }^{33,44,45}$ Although the MCAP framework includes 


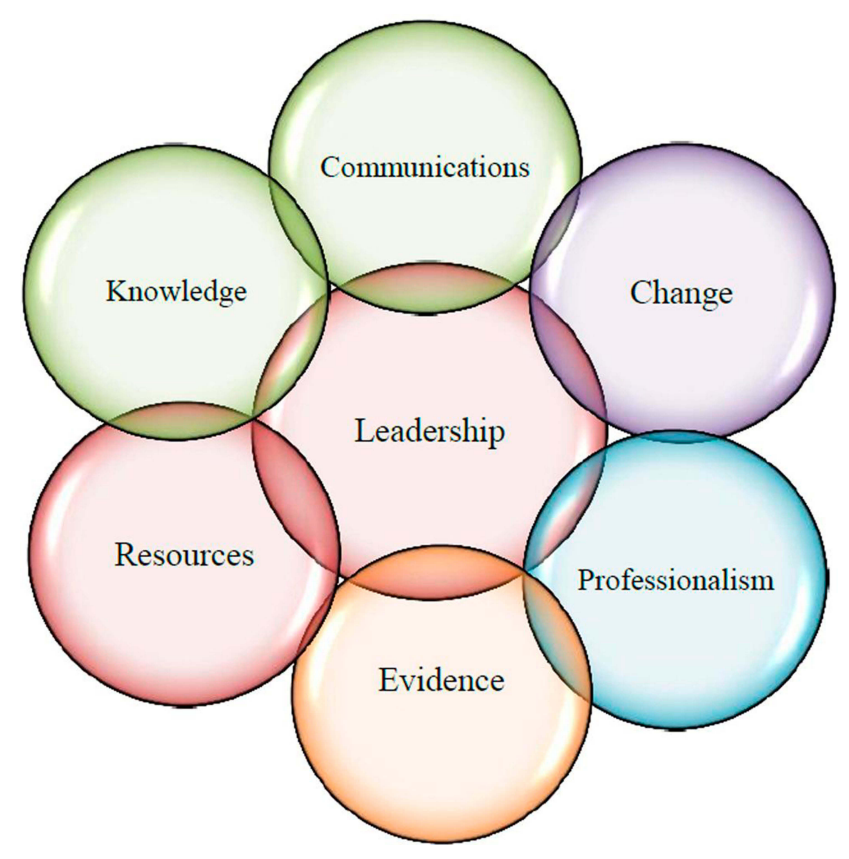

Figure 3 Final generated model of management and leadership competence for hospital managers.

behavioral items associated with the competency of professionalism, the systematic literature review and mapping confirmed the necessity of including professionalism as a separate competency for health service managers.

Professionalism is defined as

the ability to align personal and organizational conduct with ethical and professional standards that include a responsibility to the patient and community, a service orientation, and a commitment to lifelong learning and improvement. $^{46}$

Nowadays, healthcare organizations especially hospitals have adopted a patient-centred approach. For patients to receive quality service, healthcare providers need to maintain high professional and ethical standards and keep up with the most up-to-date knowledge and information. The objective is to monitor and maintain the quality and standards in the performance of managers. ${ }^{10}$ Therefore, professionalism requires development in education and training in healthcare services. ${ }^{10,32,34,46,47}$

Managers can access managerial professional development through a variety of ways. There are a number of useful mechanisms to achieve it including formal education at universities in the field of management; in-service training; in-house use of mentors and study groups; and offsite intensive training, seminars and conferences. ${ }^{48}$ To facilitate managerial development, it has been suggested that competency-based education and training for health services managers be established and adopted. ${ }^{45}$

The proposed framework together with a specific assessment process can be used for promoting, and monitoring and evaluating the competence of health service managers, guiding the design of position descriptions, recruitment, and assessing the competency gaps, hence the training needs of managers. ${ }^{49,50}$ In addition, this model can serve as a benchmark to educate and empower managers in healthcare organizations. In the short term, considering the importance of competency-based education in developing health service managers and workforce development, the identification and development of the management competency framework can not only improve the relevance of the existing informal and formal training to health service managers in meeting the management workforce needs of the healthcare industry, but also contribute to the effectiveness and efficiency of health service delivery. In the longer term, the framework reflects on the competency requirements of the overall health service management workforce providing guidance to developing system and organization-wide strategies in improving the overall workforce competency and preparing the future workforce in meeting the constant challenges and changes facing health systems.

\section{Conclusions}

The paper has presented the findings of a systematic literature review of health service management competency studies and discussed the process and results of the leadership and management competency mapping using the validated MCAP framework as the basis. As a result, an inclusive management competency framework consisting of seven core leadership and management competencies is proposed. Although the proposed framework does not clearly differentiate the variation of required competence level between sectors, management levels and positions, it provides a very useful guide for revising and developing the current healthcare management training and development curriculum and to select and recruit candidates appropriate to different management roles in the healthcare settings. In sum, the development of leadership and management competencies may strategically and systematically improve general organizational performance and essential managerial functions and will guide developing and preparing and competent managers and leaders. 


\section{Strengths and Limitations}

The review of the literature confirms that this was the first study to systematically review empirical studies focusing on the identification of leadership and management competencies for health managers, in particularly hospital managers since year 2000. All stages of the research (screening, quality appraisal, data extraction and data analysis) were performed by two researchers independently to ensure its accuracy and consistency. The main limitation of the study was that it did not differentiate the required competence level by sectors, management levels and positions. Therefore, the framework recommended may require further validation prior to use for guiding the teaching and development managers when a specific context is to be taken into consideration. However, it does provide a generic framework for understanding the overall competency development needs of health service management workforce.

\section{Acknowledgments}

The authors are grateful to the creators of the MCAP framework for their permission to use it in this study. We also thank Dr Peter Howard for assistance with language editing, proofreading and comments that greatly improved the manuscript.

\section{Author Contributions}

All authors contributed to data analysis, drafting or revising the paper, gave final approval of the version to be published and agree to be accountable for all aspects of the work.

\section{Funding}

This review was conducted as part of $\mathrm{PhD}$ thesis which was funded by the Tabriz University of Medical Science (IR.TBZMED.REC.1397.909). The funders had no role in study design, data collection and analysis, decision to publish, or preparation of the manuscript.

\section{Disclosure}

The authors declare that they have no competing interests.

\section{References}

1. Figueroa CA, Harrison R, Chauhan A, Meyer L. Priorities and challenges for health leadership and workforce management globally: a rapid review. BMC Health Serv Res. 2019;19(1):239. doi:10.1186/ s12913-019-4080-7
2. Lopes AG, Narattharaksa K, Siripornpibul T, Briggs D. An assessment of management competencies for primary health care managers in Timor-Leste. T Int J Health Plann Manage. 2019;35(2):520-531. doi:10.1002/hpm.2942

3. Kantanen K, Kaunonen M, Helminen M, Suominen T. Leadership and management competencies of head nurses and directors of nursing in Finnish social and health care. J Res Nurs. 2017;22 (3):228-244. doi:10.1177/1744987117702692

4. Rabbani F, Hashmani FN, Mukhi AAA, et al. Hospital management training for the Eastern Mediterranean Region: time for a change? J Health Organ Manag. 2015;29(7):965-972. doi:10.1108/JHOM-112014-0197

5. Kakemam E, Dargahi H. Competencies Gap in Hospital Management in Tehran, Iran: a Cross-sectional Survey. J Health Manag. 2019;21 (4):451-464. doi:10.1177/0972063419884412

6. ÉN T, Lamarche PA, Goulet L, Contandriopoulos AP. Health care system performance of 27 OECD countries. Int J Health Plann Manag. 2012;27(2):104-129. doi:10.1002/hpm.1110

7. Busari JO. Management and leadership development in healthcare and the challenges facing physician managers in clinical practice. Int J Clin Leader. 2012;17(4):211-216.

8. Coulter JS, Faulkner DC. The multigenerational workforce. Prof Case Manag. 2014;19(1):46-51. doi:10.1097/NCM.0000000000000008

9. Piper LE. Generation Y in healthcare: leading millennials in an era of reform. Front Health Serv Manag. 2012;29(1):16-28. doi:10.1097/ 01974520-201207000-00003

10. Kitreerawutiwong K, Sriruecha C, Laohasiriwong W. Development of the competency scale for primary care managers in Thailand: scale development. BMC Fam Pract. 2015;16(1):174. doi:10.1186/s12875015-0388-5

11. Pihlainen V, Kivinen T, Lammintakanen J. Management and leadership competence in hospitals: a systematic literature review. Leadersh Health Serv. 2016;29(1):95-110. doi:10.1108/LHS-11-2014-0072

12. Heshmati B, Joulaei H. Iran's health-care system in transition. Lancet. 2016;387(10013):29-30. doi:10.1016/S0140-6736(15)01297-0

13. Kalhor R, Amini S, Sokhanvar M, Lotfi F, Sharifi M, Kakemam E. Factors affecting the technical efficiency of general hospitals in Iran: data envelopment analysis. J Egypt Public Health Assoc. 2016;91 (1):20-25. doi:10.1097/01.EPX.0000480717.13696.3c

14. Raeissi P, Sokhanvar M, Kakemam E. Outsourcing in Iranian hospitals: findings from a qualitative study. Int J Health Plann Manag. 2018;33(4):e1250-e61. doi:10.1002/hpm.2619

15. Jafari M, Habibirad A, Pourtaleb A, Salarianzadeh MH. Health system organizational reform in governing Iranian public hospitals: a content analysis to comprehend the barriers in Board of Trustees' hospitals. Int $J$ Health Plann Manag. 2018;33(2):e612-e20. doi:10.1002/hpm.2500

16. Barati O, Sadeghi A, Khammarnia M, Siavashi E, Oskrochi G. A qualitative study to identify skills and competency required for hospital managers. Electron Physician. 2016;8(6):2458. doi:10.19 $082 / 2458$

17. Kalhor R, Tajnesaei M, Kakemam E, Keykaleh MS, Kalhor L. Perceived hospital managerial competency in Tehran, Iran: is there a difference between public and private hospitals? J Egypt Public Health Assoc. 2016;91(4):157-162. doi:10.1097/01.EPX.000050818 0.48823.cd

18. Lankarani KB, Alavian SM, Peymani P. Health in the Islamic Republic of Iran, challenges and progresses. Med J Islam Repub Iran. 2013;27(1):42.

19. Liang Z. Health Reforms and Australian Senior Health Executive Workforce: Characteristics, Competencies and Challenges. VDM Publishing; 2008.

20. Ackerly DC, Sangvai DG, Udayakumar K, et al. Training the next generation of physician-executives: an innovative residency pathway in management and leadership. Acad Med. 2011;86(5):575-579. doi:10.1097/ACM.0b013e318212e51b 
21. Enterkin J, Robb E, Mclaren S. Clinical leadership for high-quality care: developing future ward leaders. J Nurs Manag. 2013;21 (2):206-216. doi:10.1111/j.1365-2834.2012.01408.x

22. McCallin A, Frankson C. The role of the charge nurse manager: a descriptive exploratory study. $J$ Nurs Manag. 2010;18 (3):319-325. doi:10.1111/j.1365-2834.2010.01067.x

23. Townsend K, Wilkinson A, Bamber G, Allan C. Accidental, unprepared, and unsupported: clinical nurses becoming managers. Int J Hum Resour Man. 2012;23(1):204-220. doi:10.1080/0958 5192.2011.610963

24. Calhoun JG, Dollett L, Sinioris ME, et al. Development of an interprofessional competency model for healthcare leadership. Healthc Manag. 2008;53(6).

25. Garman A, Scribner L. Leading for quality in healthcare: development and validation of a competency model. Healthc Manag. 2011;56(6):373-384.

26. Moher D, Liberati A, Tetzlaff J, Altman DG. Preferred reporting items for systematic reviews and meta-analyses: the PRISMA statement. Ann Intern Med. 2009;151(4):264-269. doi:10.1371/journal.pmed.1000097

27. Hong QN, Pluye P, Fàbregues S, et al. Mixed Methods Appraisal Tool (MMAT), Version 2018. Canada: IC Canadian Intellectual Property Office; 2018.

28. Stretton T, Cochrane T, Narayan V. Exploring mobile mixed reality in healthcare higher education: a systematic review. Research Learn Technol. 2018;26:2131. doi:10.25304/rlt.v26.2131

29. Carroll C, Booth A, Cooper K. A worked example of" best fit" framework synthesis: a systematic review of views concerning the taking of some potential chemopreventive agents. BMC Med Res Methodol. 2011;11(1):29. doi:10.1186/1471-2288-11-29

30. Dixon-Woods M. Using framework-based synthesis for conducting reviews of qualitative studies. BMC Med. 2011;9(1):39. doi:10.1186/ 1741-7015-9-39

31. Carroll C, Booth A, Leaviss J, Rick J. "Best fit" framework synthesis: refining the method. BMC Med Res Methodol. 2013;13(1):37. doi:10.1186/1471-2288-13-37

32. Liang Z, Leggat SG, Howard PF, Koh L. What makes a hospital manager competent at the middle and senior levels? Aust Health Rev. 2013;37(5):566-573. doi:10.1071/AH12004

33. Liang Z, Howard PF, Koh LC, Leggat S. Competency requirements for middle and senior managers in community health services. Aust Health Rev. 2013;19(3):256-263. doi:10.1071/PY12041

34. Liang Z, Howard PF, Leggat S, Bartram T. Development and validation of health service management competencies. J Health Organ Manag. 2018;32(1):157-175. doi:10.1108/JHOM-06-2017-0120

35. Luo WY, Shen NP, Lou JH, He PP, Sun JW. Exploring competencies: a qualitative study of Chinese nurse managers. J Nurs Manag. 2016;24(1):E87-E94. doi:10.1111/jonm.12295
36. Van Tuong P, Thanh ND. A Leadership and managerial competency framework for public hospital managers in Vietnam. AIMS Public Health. 2017;4(4):418. doi:10.3934/publichealth.2017.4.418

37. Wongprasit $\mathrm{N}$. The leadership competencies model of private hospital directors in Thailand. HRD J. 2014;4(1):72-85.

38. Gunawan J, Aungsuroch Y, Fisher ML, McDaniel AM. Development and psychometric properties of managerial competence scale for first-line nurse managers in Indonesia. SAGE Open Nurs. 2019;5:1-12. doi:10.1177/2377960819831468

39. Connelly LM, Yoder UH, Miner-Williams D. A qualitative study of charge nurse competencies. Medsurg Nurs. 2003;12(5):299.

40. Sherman RO, Bishop M, Eggenberger T, Karden R. Development of a leadership competency model. J Nurs Adm. 2007;37(2):85-94. doi:10.1097/00005110-200702000-00011

41. Pillay R. Defining competencies for hospital management: a comparative analysis of the public and private sectors. Leadersh Health Serv. 2008;21(2):99-110. doi:10.1108/17511870810870547

42. Pillay R. The skills gap in nursing management in South Africa: a sectoral analysis: a research paper. Nurs Manag. 2010;18 (2):134-144. doi:10.1111/j.1365-2834.2010.01063.x

43. Kantanen K, Kaunonen M, Helminen M, Suominen T. The development and pilot of an instrument for measuring nurse managers' leadership and management competencies. J Res Nurs. 2015;20 (8):667-677. doi:10.1177/1744987115605870

44. Howard PF, Liang Z, Leggat S, Karimi L. Validation of a management competency assessment tool for health service managers. J Health Organ Manag. 2018;32(1):113-134. doi:10.11 08/JHOM-08-2017-0223

45. Liang Z, Blackstock FC, Howard PF, et al. An evidence-based approach to understanding the competency development needs of the health service management workforce in Australia. BMC Health Serv Res. 2018;18(1):976. doi:10.1186/s12913-018-3760-z

46. Stefl ME. Common competencies for all healthcare managers: the Healthcare Leadership Alliance model. J Healthc Manag. 2008;53 (6):60-374.

47. Dorji K, Tejativaddhana P, Siripornpibul T, Cruickshank M, Briggs D. Leadership and management competencies required for Bhutanese primary health care managers in reforming the district health system. J Healthc Leadersh. 2019;11:13-21. doi:10.2147/JHL.S195751

48. Briggs D. SHAPE declaration on the organisation and management of health services: a call for informed public debate. Asia Pac $J$ Health Manag. 2008;3(2):10.

49. Campion MA, Fink AA, Ruggeberg BJ, Carr L, Phillips GM, Odman RB. Doing competencies well: best practices in competency modeling. Pers Psychol. 2011;64(1):225-262. doi:10.1111/j.17446570.2010.01207.x

50. Sitzmann T, Ely K, Brown KG, Bauer KN. Self-assessment of knowledge: a cognitive learning or affective measure? Acad Manag Learn Educ. 2010;9(2):169-191. doi:10.5465/amle.9.2.zqr169
Journal of Healthcare Leadership

\section{Publish your work in this journal}

The Journal of Healthcare Leadership is an international, peer-reviewed, open access journal focusing on leadership for the health profession. The journal is committed to the rapid publication of research focusing on but not limited to: Healthcare policy and law;Theoretical and practical aspects healthcare delivery; Interactions between healthcare and society and evidence-based practices; Interdisciplinary decision-making;
Philosophical and ethical issues; Hazard management; Research and opinion for health leadership; Leadership assessment. The manuscript management system is completely online and includes a very quick and fair peer-review system. Visit http://www.dovepress.com/ testimonials.php to read real quotes from published authors. 